\title{
Changes in Body Iron Status, Heart Rate, and Unspecific Symptoms across Menstrual Cycle in Marginally Iron-Deficient Young Women
}

\author{
Kumiko INOUE ${ }^{1, *}$ and Michiko SugIYAMA ${ }^{2}$ \\ ${ }^{1}$ Department of Food Science and Human Nutrition, Tokyo Metropolitan College, \\ Akishima, Tokyo 196-8540, Japan \\ ${ }^{2}$ Department of Adult Health Science, the National Institute of Health \\ and Nutrition, Shinjuku-ku, Tokyo 162-0052, Japan
}

(Received March 1, 1997)

\begin{abstract}
Summary To determine the body iron status of young women, we screened female university students ( $n=910$ : 19-22 years old) in Japan for anemia. The incidence of marginal iron deficiency and iron-deficient anemia were $41.9 \%$ and $6.5 \%$, respectively. So, we investigated changes in body iron status across the menstrual cycle in the marginally iron-deficient young women. Further, heart rate and unspecific symptoms were examined concurrently. Forty-three subjects (19-22 years old) were classified by their body iron status into three groups: iron-deficient anemia (hemoglobin, $\mathrm{Hb}<12 \mathrm{~g} / \mathrm{dl}$; serum ferritin, $\mathrm{SF}<17 \mathrm{ng} / \mathrm{ml}$ ), marginal iron deficiency $(\mathrm{Hb} \geqq 12 \mathrm{~g} / \mathrm{dl}, \mathrm{SF}<17 \mathrm{ng} / \mathrm{ml})$, and adequate iron status $(\mathrm{Hb} \geqq$ $12 \mathrm{~g} / \mathrm{dl}, \mathrm{SF} \geqq 17 \mathrm{ng} / \mathrm{ml}$ ). The marginally iron-deficient group showed a significant decrease in the concentration of $\mathrm{Hb}$ and ferritin in serum and an increased resting heart rate level during the luteal phase compared with those parameters for the follicular phase. These changes were observed only in the marginally deficient group. In this group, moreover, unspecific psychological symptoms were more frequently observed than in the other two groups, and these symptoms appeared more frequently during the luteal phase than during the follicular phase. The present study suggests that the decrease in body iron status and the increase in heart rate and unspecific symptoms during the luteal phase were associated with marginal iron deficiency in these young women.
\end{abstract}

Key Words: marginal iron deficiency, young women, menstrual cycle, heart rate, unspecific symptoms

${ }^{*}$ To whom correspondence should be addressed. 
Maintenance of a proper body iron status is an important nutritional problem in young women. Especially, the incidence of marginal iron deficiency is remarkably higher than that of iron-deficiency anemia in Japan (45.9\% vs. 6.2\%) [1].

On the other hand, it has been demonstrated that indicators of nutritional status change periodically with the menstrual cycle [2-9]. However, it is still to be determined whether these changes in the nutritional indicators can be affected by marginal nutrient deficiency or not.

Thus, the present study was designed to compare the menstrual changes of indicators for body iron status in marginally iron-deficient women with that in iron-adequate or-deficient women.

\section{SUBJECTS}

From 910 women (19-22 years old), who participated in a screening for anemia at the Japan Women's University of Tokyo, 59 were diagnosed as having iron-deficiency anemia. They and 160 women who were randomly sampled from 851 non-anemic women were informed about this study protocol. Finally, 5 subjects with iron-deficient anemia and 38 subjects without anemia participated in this study and gave informed consent. The following criteria were employed to decide the subject's iron status during the luteal phase [1]:

1. Adequate $(n=15$ : hemoglobin, $\mathrm{Hb} \geqq 12 \mathrm{~g} / \mathrm{dl}$; serum ferritin, $\mathrm{SF} \geqq 17 \mathrm{ng} / \mathrm{ml})$.

2. Marginally iron deficient $(n=23: \mathrm{Hb} \geqq 12 \mathrm{~g} / \mathrm{dl}, \mathrm{SF}<17 \mathrm{ng} / \mathrm{ml})$.

3. Iron-deficiency anemia $(n=5: \mathrm{Hb}<12 \mathrm{~g} / \mathrm{dl}, \mathrm{SF}<17 \mathrm{ng} / \mathrm{ml})$.

None of the subjects were taking any iron-containing drugs. Subjects were assigned to measure their basal body temperature (BBT) every morning upon awakening to judge whether they were in the luteal phase or the follicular phase. Characteristics of the subjects, including age, menstrual cycle length, menstrual phase duration, height, weight, and body mass index (BMI), are shown in Table 1.

\section{METHODS}

Samples of venous fasting blood samples were drawn daily between 8:30 a.m.

Table 1. Characteristics of groups according to iron status.

\begin{tabular}{lccrc}
\hline Characteristics & $\begin{array}{c}\text { Adequate iron } \\
\text { status } \\
(n=15)\end{array}$ & $\begin{array}{c}\text { Marginal iron } \\
\text { deficiency } \\
(n=23)\end{array}$ & $\begin{array}{c}\text { Iron-deficiency } \\
\text { anemia } \\
(n=5)\end{array}$ & $p^{\mathrm{b}}$ \\
\hline Age (years) & $19.8 \pm 0.8^{\mathrm{a}}$ & $19.8 \pm 1.2$ & $19.4 \pm 0.8$ & 0.732 \\
Menstrual cycle length (days) & $30.8 \pm 6.3$ & $31.4 \pm 5.8$ & $27.4 \pm 3.0$ & 0.504 \\
Menstrual phase duration (days) & $5.8 \pm 1.0$ & $6.0 \pm 1.0$ & $5.8 \pm 0.7$ & 0.903 \\
Height (cm) & $157.4 \pm 4.1$ & $158.6 \pm 4.8$ & $163.1 \pm 6.1$ & 0.088 \\
Weight (kg) & $49.9 \pm 4.4$ & $52.9 \pm 5.5$ & $55.4 \pm 8.3$ & 0.137 \\
BMI & $20.2 \pm 1.5$ & $21.1 \pm 1.4$ & $20.7 \pm 2.1$ & 0.212 \\
\hline
\end{tabular}

\footnotetext{
${ }^{\mathrm{a}}$ Mean \pm SD. ${ }^{\mathrm{b}}$ By one-way ANOVA.
} 
and 9 a.m. during the subjects' luteal and follicular phases. Both phases were based on the subjects' BBT. Hb was measured by the hemoglobincyanide method (CV= $0.6 \%)[10]$. Serum iron $(\mathrm{CV}=1.5 \%)$ and total iron-binding capacity (TIBC) were analyzed according to the standards of the International Committee for Standardization in Hematology [11]. The percentage of transferrin saturation (TS) was determined by the ratio of serum iron concentration to TIBC [12]. SF was determined by an immuno-radiometric assay ( $\mathrm{CV}=2.5 \%)$ [13].

Heart rate was observed with a portable 24-h heart rate meter (Mac. VHM 1-016, VINE, Tokyo). The observed records were classified into active, rest, and sleep levels. Each heart rate level was determined according to the data from the subjects' 24-h time study records.

The incidence of unspecific symptoms during 1 week of each phase was recorded on a form filled out by each participant. The items of physical and psychological unspecific symptoms were based on Steiner's rating scale [14].

One-way analysis of variance (ANOVA) was used to investigate the distinctions among the three groups. Student's $t$-test or paired $t$-test was used to detect the differences in every possible combination.

\section{RESULTS}

\section{Iron status}

In the adequate iron status group, there was no significant difference in the $\mathrm{Hb}$ status between the luteal and follicular phases; however, SF and TS were slightly higher during the luteal phase. The marginally iron-deficient group had significantly lower $\mathrm{Hb}$ during the luteal phase $(p<0.05)$ and SF $(p<0.01)$ during both phases than the adequate iron status group. In contrast, $\mathrm{Hb}$ and $\mathrm{SF}$ during the luteal phase for this marginally deficient group were significantly lower $(p<0.05)$ than those during the follicular phase. In the iron-deficiency anemia group, $\mathrm{Hb}$, $\mathrm{SF}$, and TS were significantly lower compared with those of the adequate iron status group $(p<0.01)$ or marginally iron-deficient group $(p<0.05)$, but there were

Table 2. Body iron status during the luteal and follicular phases.

\begin{tabular}{|c|c|c|c|c|}
\hline & $\begin{array}{l}\text { Adequate iron } \\
\text { status } \\
(n=15)\end{array}$ & $\begin{array}{l}\text { Marginal iron } \\
\text { deficiency } \\
(n=23)\end{array}$ & $\begin{array}{l}\text { Iron-deficiency } \\
\text { anemia } \\
(n=5)\end{array}$ & $\begin{array}{c}\text { Menstrual } \\
\text { cycle } \\
\text { phase }\end{array}$ \\
\hline Hemoglobin $(\mathrm{g} / \mathrm{dl})$ & $\begin{array}{l}13.4 \pm 0.9^{\mathrm{a}} \\
13.5 \pm 0.8\end{array}$ & $\left.\begin{array}{l}13.2 \pm 1.0 \\
13.0 \pm 0.8^{*}\end{array}\right] * t$ & $\begin{array}{l}10.8 \pm 0.9^{* *} \\
11.0 \pm 0.8^{* *}\end{array}$ & $\begin{array}{l}\text { Follicular } \\
\text { Luteal }\end{array}$ \\
\hline Serum ferritin $(\mathrm{ng} / \mathrm{ml})$ & $\begin{array}{l}27.6 \pm 7.5 \\
30.2 \pm 11.7\end{array}$ & $\left.\begin{array}{r}11.6 \pm 8.1^{* *} \\
9.4 \pm 5.1^{* *}\end{array}\right] * t$ & $\begin{array}{l}3.7 \pm 1.4^{* *} \\
3.4 \pm 1.0^{* *}\end{array}$ & $\begin{array}{l}\text { Follicular } \\
\text { Luteal }\end{array}$ \\
\hline Transferrin saturation (\%) & $\begin{array}{l}28.7 \pm 6.6 \\
30.6 \pm 15.0\end{array}$ & $\begin{array}{l}24.8 \pm 11.4 \\
23.8 \pm 11.7\end{array}$ & $\begin{array}{l}8.2 \pm 2.5^{* *} \\
6.1 \pm 1.6^{* *}\end{array}$ & $\begin{array}{l}\text { Follicular } \\
\text { Luteal }\end{array}$ \\
\hline
\end{tabular}

${ }^{\text {a Mean }} \pm \mathrm{SD} .{ }^{*} p<0.05,{ }^{* *} p<0.01$, vs. adequate iron status group (Student's $t$-test).

${ }^{*} t p<0.05$, paired $t$-test between the luteal and the follicular phases. 
no significant differences in this group during the luteal and follicular phases (Table 2).

\section{Heart rate}

Only in the marginally iron-deficient group was the resting heart rate level during the luteal phase significantly increased compared with that in the adequate iron status group $(p<0.05)$. There were no significant differences in active or sleep heart rate levels among the three groups during the follicular or luteal phase (Table 3).

\section{Unspecific symptoms}

In the adequate iron status group, the incidence rates of physical and psychological unspecific symptoms during the luteal phase were almost equal; however, they occurred twice as frequently as those in the follicular phase (Table 4).

In the marginally iron-deficient group, physical and psychological unspecific symptoms occurred more frequently during the luteal phase than during the follicular phase. Psychological symptoms occurred more frequently in the marginally iron-deficient group than in the other two groups. Especially, abdominal bloating and constipation occurred almost twice as often during the luteal and follicular phases in the marginally iron-deficient group as in the adequate iron group. As for psychological symptoms, the frequency of anxiety in the marginally

Table 3. Heart rate levels in the three iron status groups in the luteal and follicular phases.

\begin{tabular}{lcccl}
\hline & $\begin{array}{c}\text { Adequate iron } \\
\text { status } \\
(n=15)\end{array}$ & $\begin{array}{c}\text { Marginal iron } \\
\text { deficiency } \\
(n=23)\end{array}$ & $\begin{array}{c}\text { Iron-deficiency } \\
\text { anemia } \\
(n=5)\end{array}$ & $\begin{array}{c}\text { Menstrual } \\
\text { cycle } \\
\text { phase }\end{array}$ \\
\hline Active (beats/min) & $73.2 \pm 14.8^{\mathrm{a}}$ & $79.3 \pm 15.7$ & $78.9 \pm 10.0$ & Follicular \\
& $80.0 \pm 13.3$ & $82.6 \pm 7.3$ & $77.0 \pm 5.8$ & Luteal \\
Resting (beats/min) & $70.3 \pm 7.5$ & $71.6 \pm 14.9$ & $69.4 \pm 5.8$ & Follicular \\
& $68.9 \pm 6.7$ & $78.3 \pm 5.6^{*}$ & $67.8 \pm 10.3$ & Luteal \\
Sleep (beats/min) & $63.3 \pm 18.4$ & $54.4 \pm 10.1$ & $55.3 \pm 4.2$ & Follicular \\
& $63.7 \pm 11.5$ & $58.1 \pm 6.1$ & $54.6 \pm 4.8$ & Luteal \\
\hline
\end{tabular}

${ }^{a}$ Mean \pm SD. ${ }^{*} p<0.05$, vs. adequate iron status group (Student's $t$-test).

Table 4. Incidence of unspecific symptoms in the three different iron status groups.

\begin{tabular}{lcccl}
\hline \multirow{2}{*}{ Type of symptom } & $\begin{array}{c}\text { Adequate iron } \\
\text { status }\end{array}$ & $\begin{array}{c}\text { Marginal iron } \\
\text { deficiency } \\
(n=15)\end{array}$ & $\begin{array}{c}\text { Iron-deficiency } \\
\text { anemia }\end{array}$ & $\begin{array}{c}\text { Menstrual } \\
\text { cycle }\end{array}$ \\
& $2.6 \pm 4.5^{\mathrm{a}}$ & $4.5 \pm 5.5$ & $5.3 \pm 6.1$ & Follicular \\
\hline Physical symptoms (weekly) & $4.9 \pm 5.3$ & $9.1 \pm 11.5$ & $4.5 \pm 5.1$ & Luteal \\
& $2.0 \pm 3.9$ & $7.3 \pm 8.4^{*}$ & $4.1 \pm 5.5$ & Follicular \\
Psychological symptoms (weekly) & $4.6 \pm 4.8$ & $10.0 \pm 10.3^{*}$ & $4.1 \pm 3.5$ & Luteal \\
\hline
\end{tabular}

${ }^{\mathrm{a}}$ Mean $\pm \mathrm{SD} .{ }^{*} p<0.05$, vs. adequate iron status group (Student's $t$-test). 
iron-deficient group was four times higher $(p<0.05)$ in the luteal phase and more than three times higher $(p<0.05)$ in the follicular phase compared with those of the adequate iron status group; and the incidence of depression was three times higher $(p<0.05)$ during the luteal phase and 1.5 times higher during the follicular phase.

In the iron-deficiency anemia group, unspecific symptoms occurred less frequently than in the marginally iron-deficient group and at about the same frequency as in the adequate group during the luteal phase. There was no difference in the incidence of unspecific symptoms between luteal and follicular phases for any group.

\section{DISCUSSION}

The present results indicated the incidence of iron-deficiency anemia to be only $6.5 \%$ but that of marginal iron deficiency to be $41.9 \%$. The results of mass screening of marginal iron deficiency in young women has been reported little. The incidence we found is similar to that $(45.4 \%)$ in Kariyone's study conducted in 1981 [1], indicating that the marginal iron deficiency is still prevalent among young Japanese women.

Furthermore, the marginally iron-deficient group showed a decreased iron status in serum and an increase in heart rate and unspecific symptoms during the luteal phase compared with those in the follicular phase.

With respect to the menstrual changes in iron status indicators, $\mathrm{Hb}$, ferritin, and TS in serum, no difference was found in adequate iron status group or irondeficiency anemia group in our study. On the menstrual changes of these indicators, Kim et al. [9] showed apparently no difference between follicular and luteal phase in the cross-sectional study ( $n=1,712$ : 18-44 years old) of the Second National Health and Nutrition Examination Survey. This is compatible with our result in adequate iron status group or iron-deficiency anemia group. However, in marginally iron-deficient group, we found that the concentrations of $\mathrm{Hb}, \mathrm{SF}$ were decreased significantly during the luteal phase than the follicular phase $(p<0.05)$.

With marginal iron-deficiency status, the high heart rate contributed to the heart pumping out and circulating a higher volume of blood during the luteal phase, a time at which iron metabolites tend to decrease. Whereas iron-deficiency anemia subjects maintained a normal heart rate. Their hearts received more blood from their peripheral veins and, therefore, increased the volume of blood per pump [15]. An increased heart rate is also considered to be an indicator of mental stress and/or fatigue. Thus, the increased resting heart rate level during the luteal phase may be related to high incidence of unspecific symptoms, mental stress, and fatigue.

During the luteal phase, negative psychological symptoms-such as anxiety, depression or the desire to be alone-increased significantly in the marginally iron-deficient subjects. In the anemia group, unspecific symptoms were not ob- 
served, but these individuals showed clinical symptoms (e.g., dizziness, pallor, frequent change in weight, menorrhagia). On the other hand, unspecific symptoms were observed in people with marginal nutrient deficiency [16]. Thus, the findings of this study suggest that the decrease in body iron status during the luteal phase is correlated with the changes in heart rate and unspecific symptoms across the menstrual cycle in marginally iron-deficient young women.

The authors are grateful to Dr. Norimasa Hosoya, a professor emeritus of the University of Tokyo, for various advices through the study process.

\section{REFERENCES}

1. Uchida, T., Tanaka, T., Umino, M., Shichishima, T., Kokubu, R., Yui, T., Kimura, H., Muroi, S., Matsuda, S., and Kariyone, S. (1981): Prevalence and causes of iron deficiency in Japanese women. Nihon Naikagaku, 70, 39-45.

2. Bisdee, J.T., Garlick, P.J., and James, W.P.T. (1989): Metabolic changes during the menstrual cycle. Br. J. Nutr., 61, 641-650.

3. Fong, A.K.H., and Kretsch, M.J. (1993): Change in dietary intake, urinary nitrogen and urinary volume across the menstrual cycle. Am. J. Clin. Nutr., 57, 43-46.

4. Webb, P. (1982): 24-Hour energy expenditure and the menstrual cycle. Am. J. Clin. Nutr., 36, 611-616.

5. Bisdee, J.T., James, W.P.T., and Shaw, M.A. (1989): Changes in energy expenditure during the menstrual cycle. Br. J. Nutr., 61, 187-199.

6. Lissner, L., Stevens, J., Levitsky, D.A., Rasmussen, K.M., and Strupp, B.J. (1988): Variation in energy intake during the menstrual cycle: Implications of food-intake research. Am. J. Clin. Nutr., 48, 956-962.

7. Bowen, D., and Grunberg, N.E. (1990): Variation in food preference and consumption across the menstrual cycle. Physiol. Behav., 47, 287-291.

8. Tarasuk, V., and Beaton, G.H. (1991): Menstrual-cycle pattern in energy and macronutrient intake. Am. J. Clin. Nutr., 53, 442-447.

9. Kim, I., Yetley, A.E., and Calvo, S.M. (1993): Variations in iron-status measured during the menstrual cycle. Am. J. Clin. Nutr., 58, 705-709.

10. Matsubara, T., Okuzono, H., and Senba, U. (1979): A modification of Van KampenZijlstra's reagent for the hemoglobincyanide method. Clin. Chim. Acta, 93, 163-164.

11. International Committee for Standardization in Hematology (1978): Recommendations for measurement of serum iron in human blood. Br. J. Hematol., 38, 291-294.

12. International Committee for Standardization in Hematology (1978): The measurement of total and unsaturated iron binding capacity in serum. Br. J. Hematol., 38, 281-290.

13. Addison, G.M., Beamish, M.R., Hales, C.N., Hodgkins, M., Jacobs, A., and Llewellin, P. (1972): An immunoradiometric assay for ferritin in the serum of normal subjects and patients with iron deficiency and iron overload. J. Clin. Pathol., 25, 326-329.

14. Steiner, M., Haskett, R.F., and Carroll, B. (1980): Premenstrual tension syndrome: The development of research diagnostic criteria and new rating scales. Acta Psychiatr. Scand., 62, 177-190.

15. Katou, K., Yano, I., Fujiwara, M., Hoshino, K., and Ogawa, K. (1990): Cardiac functions of rest or active levels in iron-deficient anemia. Shounika Rinshou, 43, 873-882.

16. Horning, D. (1982): Impact of marginal vitamin C deficiency. J. Jpn. Soc. Clin. Nutr., 3, 127-141. 